Chapter 5

\title{
Glycan Profiling of Adult T-Cell Leukemia (ATL) Cells with the High Resolution Lectin Microarrays
}

\author{
Hidekatsu Iha and Masao Yamada \\ Additional information is available at the end of the chapter
}

http://dx.doi.org/10.5772/55386

\section{Introduction}

\subsection{Roles of glycans on diverse aspects of biological activities}

Regardless of species, all the living organisms have poly-saccharides called glycans in their cellular surfaces or even inside the cells. The biological roles of carbohydrates are particularly important in the assembly of complex multicellular organs, which requires interactions between cells and the surrounding matrix. All cells and numerous macromolecules in nature carry an array of covalently attached sugars (monosaccharides) or sugar chains (oligosaccharides). Because many glycans are on the outer surface of cells or secreted macromolecules, they are acting to modulate or mediate a wide variety of events in cell to cell, cell with matrix, and cell with proteins or lipids critical to the development and function of complex forms of multicellular organisms (Rademacheret al., 1988; Sharon and Lis, 1993; Varki, 1993).

Glycans also function as mediators in the interactions between different organisms, for example, between hosts and infectious agents or symbionts. In addition, simple, rapidly turning over, protein-bound glycans are abundant within the nucleus and cytoplasm, where they act as regulatory switches. Therefore, as a complete paradigm of biology, glycans should be included quite often in covalent combination with other macromolecules such as glycoproteins and glycolipids, so called glycoconjugates (Gagneux and Varki, 1999).

Figure 1 provides a listing of known glycan-protein or glycan-lipid linkages in nature. The common classes of glycans found in or on eukaryotic cells are primarily defined according to the nature of the linkage to the targets. A glycoprotein is a glycoconjugate in which a protein carries one or more glycans covalently attached to a polypeptide backbone, usually via $\mathrm{N}$ or O linkages. An N-glycan ( $\mathrm{N}$ or asparagine-linked oligosaccharide) is a sugar chain covalently attached to an asparagine residue of a polypeptide chain at the consensus peptide sequence: 
Asn-X-Ser/Thr. A mucin is a large glycoprotein that carries many O-glycans that are clustered. A proteoglycan is a glycoconjugate that has one or more glycosaminoglycan (GAG) chains attached to a "core protein" through a typical core region ending in a xylose residue that is linked to the hydroxyl group of a serine residue. The distinction between a proteoglycan and a glycoprotein is otherwise arbitrary, because some proteoglycan polypeptides carry both glycosaminoglycan chains and different O- and N-glycans. A glycophosphatidylinositol anchor is a glycan bridge between phosphatidylinositol and a phosphoethanolamine that is in amide linkage to the carboxyl terminus of a protein. This structure typically constitutes the only anchor to the lipid bilayer membrane for such proteins. A glycosphingolipid (often called a glycolipid) consists of a glycan usually attached via glucose or galactose to the terminal primary hydroxyl group of the lipid moiety ceramide, which is composed of a long chain base (sphingosine) and a fatty acid. Glycolipids can be neutral or anionic. A ganglioside is an anionic glycolipid containing one or more residues of sialic acid. It should be noted that these represent only the most common classes of glycans reported in eukaryotic cells. There are several other less common types found on one or the other side of the cell membrane in animal cells (Varki, 1997; Fuster and Esko, 2005).

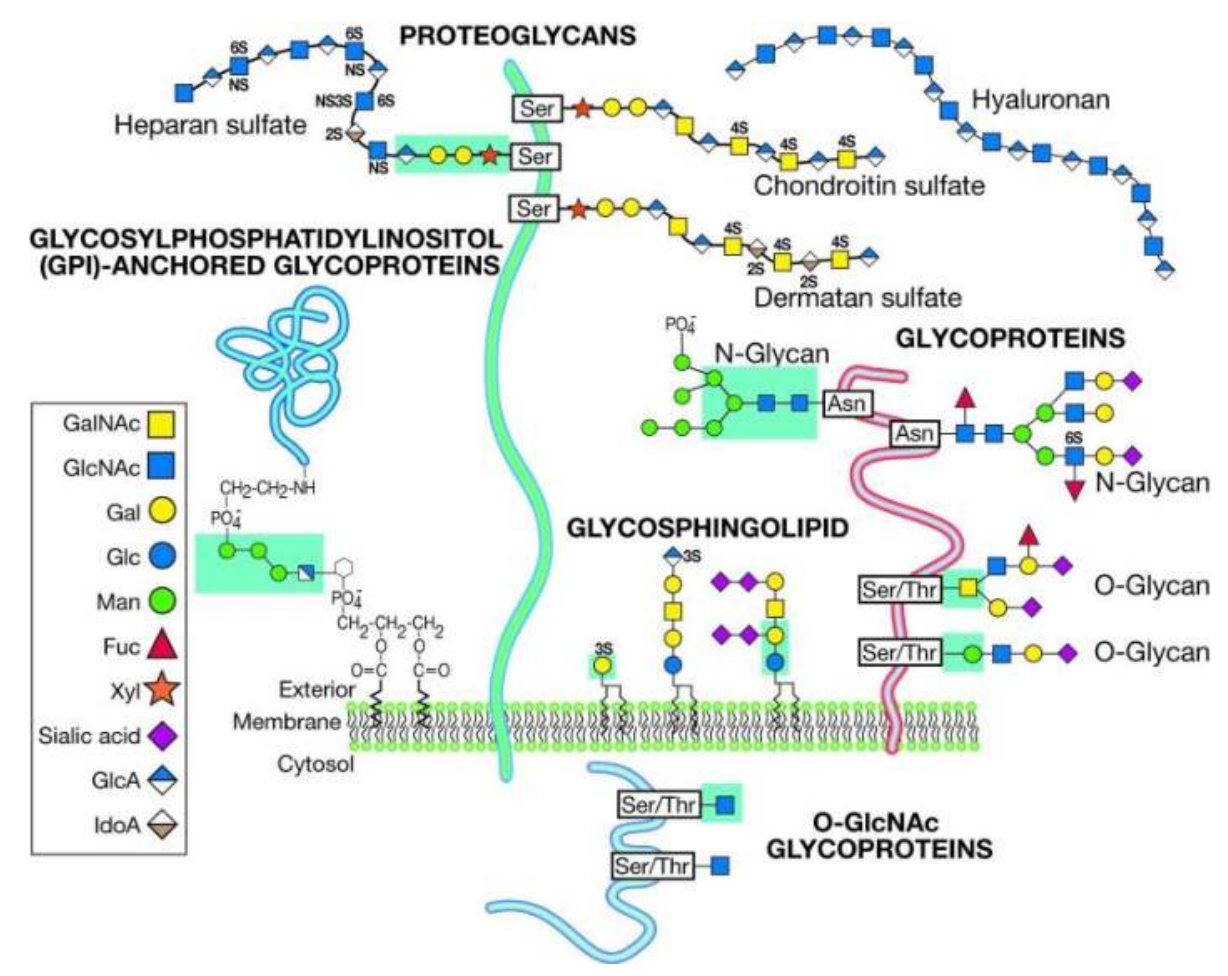

$\overline{\text { From Essentials of }}$ Glycobiology second edition (2007)

Figure 1. Glycans on surface or inside the cells 
As can be imagined from their ubiquitous and complex nature, the biological roles of glycans are quite diverse spanning the spectrum from those that are subtle to those that are crucial for the development, growth, function, or survival of an organism. The diverse functions attributed to glycans can be divided into two general categories: (i) structural and modulatory functions (involving the glycans themselves or their modulation of the molecules to which they are attached) and (ii) specific recognition of glycans by glycan-binding proteins, called lectin. Expression of certain sets of glycans in intact organisms are found exquisitely specific temporal and spatial patterns those glycans in relation to cellular activation, embryonic development, organogenesis, and differentiation. Certain relatively specific changes in expression of glycans are also often found in the course of transformation and progression to malignancy, as well as other pathological situations such as inflammation. These spatially and temporally controlled patterns of glycan expression imply the involvement of glycans in many normal and pathological processes, the precise mechanisms of which are not well understood (Theocharis, 2010; Hynes and Naba, 2012).

\section{Glycans as the markers of cancer}

Tumor cells undergo alteration of intracellular signalings to promote cell cycle progression and rapid growth, adhere to a variety of other cell types and cell matrices, and invade tissues. Embryonic development and cellular activation in vertebrates are typically accompanied by changes in cellular glycosylation profiles. It is therefore rational that glycosylation changes are also a typical feature of malignant transformation and tumor progression. The earliest evidence came from observing that plant lectins showed enhanced binding to and agglutination of tumor cells. Next, it was found that in vitro transformation was frequently accompanied by a general increase in the size of metabolically labeled glycopeptides produced by trypsinization of surface molecules from cancer cells (Hakomori and Kannagi, 1983). With the advent of monoclonal antibody technology in the late 1970s, investigators found many "tumor-specific" antibodies which were directed against glycan epitopes, especially those borne on glycosphingolipids (Feizi, 1985). In most cases, further studies showed that these epitopes were also expressed in embryonic tissues and, in a few cell types, in the normal adult (Fukuda, 1996). Significant correlations between certain types of altered glycosylation and the prognosis of tumor-bearing animals or patients increased interest in these changes. In several instances, in vitro cellular assays and in vivo animal studies have further supported the view that these changes are critical to aspects of tumor cell behavior (Kannagi et al., 2004).

\section{HTLV-1 causes complicated forms of diseases to human}

Human T-lymphotropic virus type 1 (HTLV-1) is the first and unique oncogenic retrovirus that infects 20 million more people worldwide (Hinuma et al., 1992; Proietti et al., 2005; Gonçalves et al., 2010; Sonoda et al., 2011). Among these infected individuals, 2 to 5\% develop aggressive and mostly fetal adult T cell leukemia/lymphoma: ATL (Yoshida, 2010; Iwanaga et 
al., 2010), and a further 1 to $2 \%$ develop a variety of chronic inflammatory syndromes, known as HTLV-1-associated myelopathy/tropical spastic paraparesis: HAM/TSP (Osame et al., 1986) and HTLV-1-associated uveitis: HU (Mochizuki et al., 1992). HTLV-1 has also linked, even with less definitive epidemiologic proof, dermatitis (La Grenade et al., 1990; Amano et al., 2011), polymyositis (Inose et al., 1992), synovitis (Nishioka et al., 1989; Sowa, 1992), thyroiditis (Kawai et al., 1991) and bronchio-alveolar pneumonitis (Kimura et al., 1989). While the pathophysiologies of patients with HAM/TSP and HU have relatively been well controlled, the efficacy of present treatment procedures to ATL are quite insufficient and leading ATL as one of the worst blood cell malignancies to cure (Olière et al., 2011; Tsukasaki, 2012). Researchers hence are trying to develop any diagnostic tools enabling to identify the high risk carriers (who may develop ATL) in the early phase of infection.

HTLV-1 seropositivity is corresponding to the modes of transmission: from mother to child, predominantly through breast feeding as the initiation for common course of ATL development (Hino et al., 1985); via sexual intercourse and via parenteral transmission by transfusion of infected cellular blood products or sharing of needles and syringes as the courses for HAM/ TSP or HU onset (Manns et al., 1991, Proyetti 2005). HTLV-1 infection mostly happens to CD4 T-lymphocytes (Gallo et al., 1982), and multiple viral proteins are produced from the provirus. Among those viral proteins, HTLV-1 trans-activator protein Tax, which promotes the early events of oncogenic process including its own long-terminal-repeat (LTR) transcription (Fujisawa et al., 1985), activates several major cellular transcription factor pathways, such as nuclear factor (NF)-kappaB (Ruben et al., 1988; Yamaoka et al., 1998), cAMP response element binding protein (CREB)/AP-1 transcription factor (ATF, Andrisani et al., 1990; Xu et al., 1990; Himes, 1993), and serum response factor (SRF, Fujii et al., 1991), all of which eventually mediate viral immortalization. Tax targeted genes include interleukin (IL)-2 and the IL-2alpha receptor (Tac or CD25), which initiate and sustain an autocrine pathway of T-cell activation (Ruben et al., 1988). On the late stage of ATL development, infected cell undergoes extensive genetic alterations and some of these populations induce aberrant micro-RNA expression (Yeung et al., 2008) resulting in overexpression of NIK, a strongest NF-kappaB inducing MAP3 kinase, and cells eventually become independent from Tax-mediated NF-kappaB signaling (Yamagishi et al., 2012). Finally, another HTLV-1 encoded oncogenic trans-activator, HTLV-1-basiczipper protein (HBZ), induces Foxp3, a transcription factor necessary for maintenance of the regulatory T-cell phenotype, to develop immune-suppressive environment which is favorable to establish malignant phenotype of ATL (Gaudray et al., 2002; Satou et al., 2008).

ATL cells display several characteristic 'ATL-specific' cell surface markers such as CD25, OX40, and TSLC1 (Teshigawara et al., 1985; Baum et al., 1994; Sasaki et al., 2005). Japanese HTLV-1 cohort study group, however, have reported that the most reliable molecular based definitive risk factors for the development of ATL among asymptomatic HTLV-1 carriers are baseline proviral load higher than 4 copies/100 peripheral blood mononuclear cells. Although advanced age, family history of ATL, and first opportunity for HTLV-1 testing during treatment for other diseases have also determined as the independent risk factors for ATL prognosis (Iwanaga et al., 2010), we still do not know how many cellular factors and to what extent in HTLV-1 infected subjects contribute to ATL pathogenesis nor which biomarkers distinctly determine the wide 
ranges of ATL pathological conditions (i.e., smoldering, chronic or acute leukemia or lymphoma).

\section{Linkage between efficacy and subtypes of ATL symptoms}

Shimoyama (1991) first proposed the diagnostic criteria to classify four clinical subtypes of ATL: (1) Smoldering type, 5\% or more abnormal lymphocytes of T-cell nature in PBL, no hypercalcaemia (corrected calcium level less than $2.74 \mathrm{mmol} / \mathrm{l}$ ), lactate dehydrogenase (LDH) value of up to $1.5 \mathrm{x}$ the normal upper limit, no lymphadenopathy, no involvement of liver, spleen, central nervous system (CNS), bone and gastrointestinal tract, and neither ascites nor pleural effusion. Skin and pulmonary lesion(s) may be present. (2) Chronic type, absolute lymphocytosis ( $4 \times 10^{9} / 1$ or more) with T-lymphocytosis more than $3.5 \times 10^{9} / 1$, LDH value up to twice the normal upper limit, no hypercalcaemia, no involvement of CNS, bone and gastrointestinal tract, and neither ascites nor pleural effusion. Lymphadenopathy and involvement of liver, spleen, skin, and lung may be present, and $5 \%$ or more abnormal Tlymphocytes are seen in PBL in most cases. (3) Lymphoma type, no lymphocytosis, $1 \%$ or less abnormal T-lymphocytes, and histologically-proven lymphadenopathy with or without extranodal lesions. (4) Acute type, remaining ATL patients who have usually leukemic manifestation and tumor lesions, but are not classified as any of the three other types. Smoldering and chronic subtypes are indolent but once these group become acute subtype, the mean survival period even with the best protocol of chemotherapy, mLSG15, is only 13 months and overall two year survival ratio is only 25\% (Tsukasaki, 2012).

To improve the poor prognosis of ATL, new chemical combinations or new biological treatment, including antibody targeting, immune activation by vaccination or bone marrow transplantation have developed (Tsukasaki et al., 2009; Nasr et al., 2011; Nakano and Watanabe, 2012).

Bazarbachi and his colleagues reported that treatment in combination of anti-virus drug zidovudine (AZT) and interferon-alpha (IFN- $\alpha$ ) have dramatically improved the five year survival rate of ATL patients up to $46 \%$ (Bazarbachi et al., 2010). AZT/ IFN- $\alpha$ protocol is the most promising for ATL treatment at present but it is not omnipotent for the following reason. This study was applied for all four different ATL subtypes and achieved $77 \%$ five-year survival rate for smoldering/chronic and $28 \%$ for acute subtype respectively. For lymphoma subtype however this protocol had no effects with 7-month median and no further survival beyond 18 month after treatment. This result clearly indicated that the novel fine and reliable subtypespecific diagnostics for asymptomatic but high-risk carriers are urgently required.

\section{Glycans as the potential biomarkers for ATL subtypes}

It's been thirty seven years since Van Beek reported the relationship between the malignancy and glycoprotein distribution on the surface of leukemic cells (Van Beek et al., 1975). Then 
Dnistrian claimed the plasma lipid-bound sialic acid as a diagnostic marker for hematologic tumors as well as other carcinomas (Dnistrian and Schwartz, 1981). Ohmori and his colleagues first reported that a distinct type of sialyl Lewis $\mathrm{X}$ antigen is selectively expressed on helper memory T cells and also on ATL cells which are defined by the monoclonal antibody 2F3 (Ohmori et al., 1993) and Sanada et al. reported that ATL patient's levels of serum hyaluronic acid moved in parallel with the clinical activity of their disease (Sanada et al., 1999). These reports clearly indicate that glycans should play very important roles on a tumorigenic development of hematologic malignancy. However the complicated nature of carbohydrates have hindered the development of diagnostic tools providing a statistically reliable values which eventually define the linkage between glycans and tumor malignancies. To do so, this device should quantitate the amount of multiple forms of glycans at one time and perform multivariate analysis.

\section{Lectin microarray as the profiler of ATL cell pathogenic development}

There are basically three major processes in glycomics research: (1) glycan synthesis, (2) glycan structural analysis and (3) glycan functional analysis. Glycan structural analysis is considered the first priority as it elucidates the biological functions of the glycans. It is not that simple as DNA or peptide sequencing is resolving most of questions because glycans are not linear-chain molecules but having varieties of branching molecular structures.

Our strategy in glycomics takes a different approach from that used in genomics. We have adopted the use of lectins as so-called "biological decipherers" of glycan structures, capitalizing on their binding specificity to glycan structures. Further, a microarray strategy allows us to utilize a number of lectins with different specificity thereby enabling 'glycome' analyses of small sample amounts with high sensitivity and high throughput (Kuno A et al., 2005).

Mass spectroscopy (MS) is one possible alternative approach used in glycomic structural analysis. MS potentially is a very powerful tool; however it is not versatile enough to be used since MS is not suitable for differentiation of isomers, analysis of O-glycans, and not applicable for crude samples. MS basically requires fairly large samples sizes (>100 $\mu \mathrm{g}$ of proteins) due to its low resolution. Additionally, pre-treatment of the samples on glycan structural analysis by MS is time consuming and bothersome (Pre-treatments requires the isolation of glycoproteins, cleaving of the glycans from the core proteins, and those labeling). From those practical views, the lectin microarray methodology is potentially very powerful for glycomic analysis: (1) quick and easy to use: structural profiling can be performed directly on fluorescence-labeled glycoproteins; no need of glycan cleavage from proteins, (2) highly sensitive: 1 - $100 \mathrm{ng}$ order of glycoproteins is good enough, and (3) high-throughput: benefit of microarray format. To note however, the inference performance of the lectin microarray may not be sufficient as that of MS.

One of the most noteworthy features of basic glycomics research is the weak interaction of glycans and lectins (by more than two orders of magnitude) compared with that of antibodies and antigens as well as nucleotide's hydrogen bonds. This fact inevitably created a need for a 
new technology which is capable of detecting very weak glycan-lectin interactions directly from a liquid phase without any washing process that is indispensable in DNA microarrays or in ELISA assays to remove non-specific bindings and extra amounts of labeled molecules floating in the liquid phase.

The GlycoStation ${ }^{\mathrm{TM}}$ and LecChip ${ }^{\mathrm{TM}}$ (lectin microarray containing 45 different lectins immobilized on a slide glass, GP Biosciences, Japan) employs novel 'evanescent-field fluorescence excitation (EFFEX)' technologies were thus developed to obtain specific and highly sensitive glycan-lectin interactions without washing (Fig. 2A). In this scanner, the excitation light bundle incidents into a slide glass from the edge at an appropriate incident angle to form total internal reflection at the interfaces between slide glass and sample solution. A configuration adopted in this scanner will be the simplest and easiest one which is able to generate the evanescentfiled as large as slide glass size (US Patent 6,787,364,2004). Under such conditions, an evanescent-field is formed on the surface of the lower refractive index side. The strength of evanescent-field decreases exponentially as the distance increases from the slide surface. The evanescent-field depth defined by the distance that the field strength drops to 1/e ranges from $100 \mathrm{~nm}$ to $200 \mathrm{~nm}$ (it depends on the wavelength of excitation light adopted). Because of this nature, floating glycans in a liquid phase only shows very low excitation in the evanescent field, but glycans interacting with lectins can be excited effectively (Fig. 2B) and very weak molecular interactions between glycans and lectins are monitored efficiently from the liquid phase samples without any washing (Fig. 2C). GlycoStation can be used for screening and understanding how partial glycan structures on cell surfaces change depending on the condition of the cells (i.e., cancer, disease, cell differentiation stage and so on); and to elucidate the roles glycans play and to understand the correlation between glycoforms and cell conditions. We therefore applied this system for evaluation of ATL cell pathogenic developments.

\section{Lectin microarray reveals ATL cell specific lectin binding profiles}

Conventional diagnosis on leukemia/lymphoma basically takes the following three methods, (1) microscopic observation of tumor cell morphologies with staining by Giemsa, HE/MPO, (2) quantitation of cellular surface marker molecules (glycoproteins usually) with fluorescence activated cell sorter (FACS), and (3) karyotypic or molecular genetic diagnosis on chromosome DNA. All these techniques require expertise and sometimes, especially through microscopic observations, diagnosis varies because of their less quantitative nature.

In the case of ATL diagnosis, as mentioned above, four different subtypes are classified by PBL counts and antibodies against HTLV-1 glycoproteins, biochemical values (calcium and LDH), and morphological observations of HTLV-1 infected lymphocytes. Cellular surface markers such as CD4, CD25 and provirus load are also measured for detailed analysis. Even with these criteria, however, early diagnosis for these subtype classification is not applicable.

Therefore, we may explore to see how accurately lectin microarray identifies the subtypes of ATL with multiple lectin-glycan interaction (LGI) values by Lectin array/ Glycostation. As a preliminary experiment, we evaluated the LGI values of the following six different of 


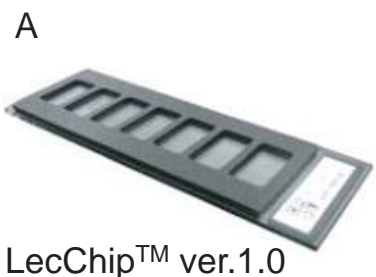

LecChip $^{\mathrm{TM}}$ ver.1.0

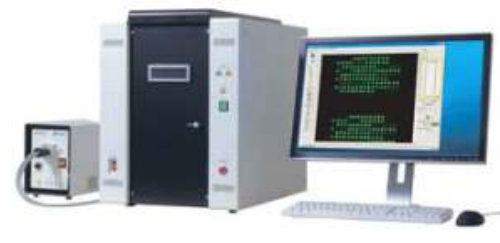

GlycoStation $^{\text {TM }}$ Reader 1200

B

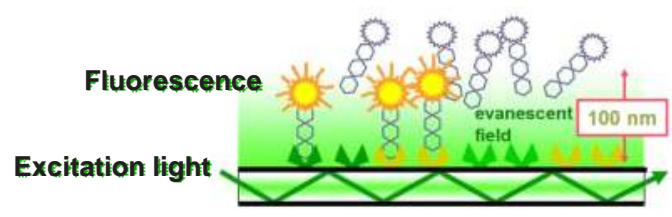

C

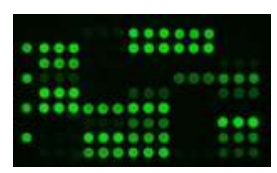

Fluorescence signals on the slide

Figure 2. Principles and devices of LecChip lectin microarray

cell, (1) two subjects of CD3+, CD4+ Helper T-cells (PBL-M, PBL-I) from healthy volunteers, (2) two subjects of HTLV-1 transformed cells (C8166, ED), and (3) two subjects of CD25+ ATL patient's peripheral blood cells (ATL4, ATL9). While PBL showed uniformly distributed relatively small cells, all ATL cells are large (twice as PBL-M or -I). ATL cells show aggregation clusters (glycans might be involved in these morphogenesis) and the extents of aggregation in these four subjects are, from high to low, in order of C8166, ATL4, ATL9 and ED (no aggregation, Fig. 3A). Then, we evaluated NF- $\kappa B$ activation level of these six subjects by western blot (WB) analysis (Fig. $3 \mathrm{~B}$ ). To evaluate how NF- $\kappa$ B is activated, cellular lysates from six subjects were fractionated into cytoplasmic (Cyt) and nuclear (Nuc) fractions. PBLs from healthy carriers, of course, don't express Tax (lane 1 to 4), C8166 expresses Tax in highest level (lane 8, 9), ATL4 and AT9 express less amount (lane 5 to 8) and ED doesn't (lane 11, 12). In accordance with Tax expression, the amount of I- $\kappa \mathrm{B} \alpha$ was decreased in C8166 most and in ATL4 next. Two PBLs show the same levels of I- $\kappa \mathrm{B} \alpha$ and in the case of ATL9 and ED, I- $\kappa \mathrm{B} \alpha$ was accumulated in cytoplasm with very high amount. p65, a main species of NF- $\kappa B$ then accumulated in nucleus in C8166 most and, surprisingly, ATL9 and ED also showed its accumulation with almost equivalent amount of ATL4. 


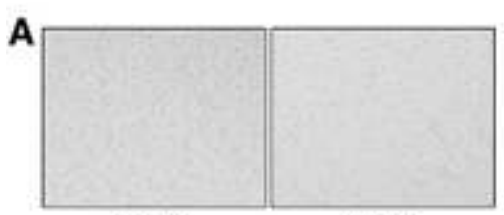

PBL-M

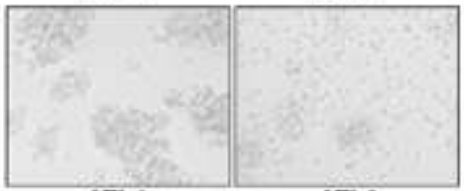

ATL4

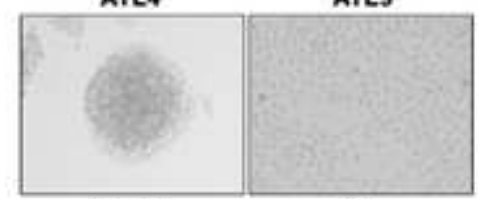

C8166
B
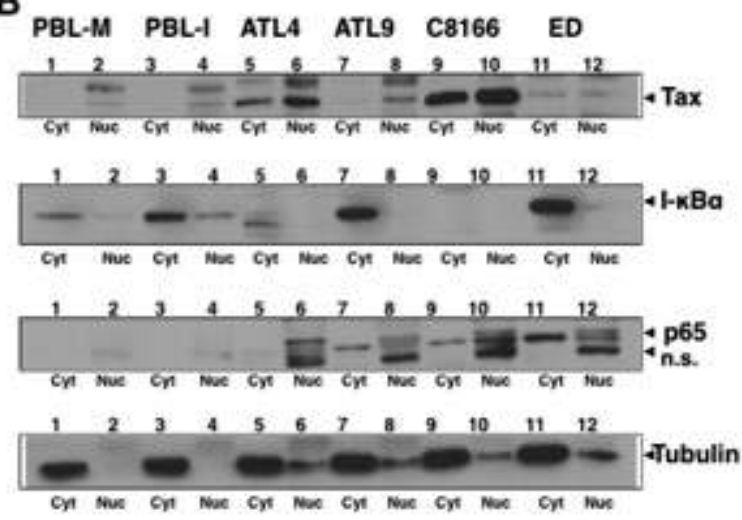

Figure 3. Cell aggregation characteristics and Tax-NF-KB activation properties of ATL cells

From these observations, we concluded the characterizations of these cells as follows; (1) C8166 and ATL4 are to be characterized as Tax-high and heavy cell aggregation types, (2) ATL9 is Tax-low and moderate cell aggregation type, and (3) ED is no-Tax and dispersed type. One can imagine that the former type is sticky and accumulate easily to peripheral lymph nodes and the latter is circulating in the blood vessels as leukemic cells.

Taking cytological characteristics mentioned above into consideration, we evaluated membrane glycoprotein fractions extracted from the six subjects by LecChip ${ }^{\mathrm{TM}} /$ GlycoStation $^{\mathrm{TM}}$. Two PBLs showed very similar glycan profiles, but the other ATL samples showed various glycan profiles. Concretely speaking, the expression levels of glycans interacting with nine different lectins (AAL, MAL, PHA(E), DSA, ACG, LEL, Jacalin, ACA, WGA) were higher in C8166 comparing with PBL, and inversely seven different lectins (SNA, SSA, TJA-I, NPA, GNA, HHL Calsepa) showed lower interaction to those of C8166. In the case of ATL4, eight out of nine lectins (except for WGA) listed in C8166 showed higher interactions, and the same set of seven lectins showed lower profiles. One thing we have to emphasize here for ATL4 is that SNA, SSA, TJA-I which have binding specificity to $\alpha 2,3-N e u A c$ showed significantly lower expression comparing with others. In the case of ATL9, the six lectin interactions (RCA120, PHA(E), DSA, BPL, PWM, Jacalin) were higher, and five lectins (NPA, GNA, HHL, TxLC-I, EEL) were lower. Finally, in the case of ED, seven lectins (AAL, PHA(E), DSA, LEL, Jacalin, WGA) interact higher, and other seven lectins (SNA, SSA, TJA-I, NPA, GNA, HHL, EEL) got lower.

Using those digitized lectin intensities, we performed clustering analysis of these six subjects by NIA Array Analysis (http://gsun.grc.nia.nih.gov/ANOVA/). Fig. 4 shows the clustering results. It is easily appreciated that (1) two PBLs behave very similar manners, (2) C8166 and 
ATL4 form the same cluster, (3) ED, non-Tax and dispersed, distinctive from other three cell lines, showed larger distance from others, and (4) ATL9, low-Tax and moderate cell aggregation, positioned between ED and C8166, ATL4.

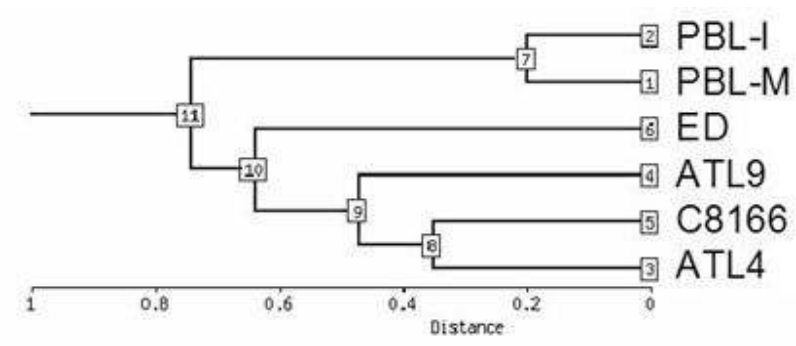

Figure 4. Hierarchical clustering of the six subject's glycan profiles

These results indicated that lectin microarray analysis detected the subtle differences of glycan profiles which synchronized with Tax-expression, NF- $\kappa$ B activation and cellular aggregation behaviors and this novel method would provide a diagnostic criteria for ATL's pathological development.

\section{Acknowledgements}

We thank Dr. M. Tomita for providing the opportunity of review article. Ms. E. Ikebe provided all the results presented in this article. E.I. is a research fellow of the Okinawa Science and Technology Promotion Center. This study is supported in part by grants from Japan Science and Technology Agency; Ministry of Education, Culture, Sports, Science, and Technology; Ministry of Economy, Trade and Industry; Okinawa Science and Technology Promotion Center; Miyazaki Prefectural Industrial Support Foundation; and the Research fund of Hita Tenryosui Co. Ltd.

\section{Author details}

Hidekatsu Iha $^{1^{*}}$ and Masao Yamada ${ }^{2}$

*Address all correspondence to: hiha@oita-u.ac.jp

1 Department of Microbiology, Oita University Faculty of Medicine, Idaigaoka, Hasama, Yufu, Japan

2 GP Biosciences Ltd, -3-3, Azamino-minami, Aoba-ku, Yokohama, Japan 


\section{References}

[1] Amano, M, Setoyama, M, Grant, A, \& Kerdel, F. A. Int J Dermatol. (2011). Human Tlymphotropic virus 1 (HTLV-1) infection-dermatological implications., 50(8), 915-920.

[2] Andrisani, O, \& Dixon, J. E. J Biol Chem. (1990). Identification and purification of a novel 120-kDa protein that recognizes the cAMP-responsive element., 265, 3212-3218.

[3] Bazarbachi, A, \& Plumelle, Y. Carlos Ramos J, Tortevoye P, Otrock Z, Taylor G, Gessain A, Harrington W, Panelatti G, Hermine O. J Clin Oncol. (2010). Meta-analysis on the use of zidovudine and interferon-alfa in adult T-cell leukemia/lymphoma showing improved survival in the leukemic subtypes., 28, 4177-4183.

[4] Baum, P. R, \& Gayle, R. B. rd, Ramsdell F, Srinivasan S, Sorensen RA, Watson ML, Seldin MF, Baker E, Sutherland GR, Clifford KN, et al. EMBO J. (1994). Molecular characterization of murine and human OX40/OX40 ligand systems: identification of a human OX40 ligand as the HTLV-1-regulated protein gp34., 13, 3992-4001.

[5] Dnistrian, A. M, \& Schwartz, M. K. Clin Chem. (1981). Plasma lipid-bound sialic acid and carcinoembryonic antigen in cancer patients., 27, 1737-1739.

[6] Feizi, T. Nature. (1985). Demonstration by monoclonal antibodies that carbohydrate structures of glycoproteins and glycolipids are onco-developmental antigens., 314, 53-57.

[7] Fujii, M, Niki, T, Mori, T, Matsuda, T, Matsui, M, Nomura, N, \& Seiki, M. Oncogene. (1991). HTLV-1 Tax induces expression of various immediate early serum responsive genes., 6, 1023-1029.

[8] Fujisawa, J, Seiki, M, Kiyokawa, T, \& Yoshida, M. Proc Natl Acad Sci U S A. (1985). Functional activation of the long terminal repeat of human T-cell leukemia virus type I by a trans-acting factor., $82,2277-2281$.

[9] Fukuda, M. Cancer Res. (1996). Possible roles of tumor-associated carbohydrate antigens., 56, 2237-2244.

[10] Fuster, M. M, \& Esko, J. D. Nat Rev Cancer. (2005). The sweet and sour of cancer: glycans as novel therapeutic targets., 5, 526-242.

[11] Gagneux, P, \& Varki, A. Glycobiology. (1999). Evolutionary considerations in relating oligosaccharide diversity to biological function., 9, 747-755.

[12] Gallo, R. C, Mann, D, Broder, S, Ruscetti, F. W, Maeda, M, Kalyanaraman, V. S, \& Robert-guroff, M. Reitz MS Jr. Proc Natl Acad Sci U S A. (1982). Human T-cell leukemia-lymphoma virus (HTLV) is in T but not B lymphocytes from a patient with cutaneous T-cell lymphoma., 79, 5680-5683.

[13] Gaudray, G, Gachon, F, Basbous, J, Biard-piechaczyk, M, Devaux, C, \& Mesnard, J. M. J Virol. (2002). The complementary strand of the human T-cell leukemia virus 
type 1 RNA genome encodes a bZIP transcription factor that down-regulates viral transcription., 76, 12813-12822.

[14] Gonçalves, D. U, Proietti, F. A, Ribas, J. G, Araújo, M. G, Pinheiro, S. R, Guedes, A. C, \& Carneiro-proietti, A. B. Clin Microbiol Rev. (2010). Epidemiology, treatment, and prevention of human T-cell leukemia virus type 1-associated diseases., 23, 577-589.

[15] Hakomori, S, \& Kannagi, R. J Natl Cancer Inst. (1983). Glycosphingolipids as tumorassociated and differentiation markers., 71, 231-251.

[16] Himes, S. R, Coles, L. S, Katsikeros, R, Lang, R. K, \& Shannon, M. F. Oncogene. (1993). HTLV-1 tax activation of the GM-CSF and G-CSF promoters requires the interaction of NF-kB with other transcription factor families., 8, 3189-3197.

[17] Hinuma, Y, Nagata, K, Hanaoka, M, Nakai, M, Matsumoto, T, Kinoshita, K. I, Shirakawa, S, \& Miyoshi, I. Proc Natl Acad Sci U S A. (1981). Adult T-cell leukemia: antigen in an ATL cell line and detection of antibodies to the antigen in human sera., 78, 6476-680.

[18] Hynes, R. O, \& Naba, A. Cold Spring Harb Perspect Biol. (2012). 4:a004903. Overview of the matrisome--an inventory of extracellular matrix constituents and functions.

[19] Inose, M, Higuchi, I, Yoshimine, K, Suehara, M, Izumo, S, Arimura, K, \& Osame, M. J Neurol Sci. (1992). Pathological changes in skeletal muscle in HTLV-I-associated myelopathy., 110, 73-78.

[20] Iwanaga, M, Watanabe, T, Utsunomiya, A, Okayama, A, Uchimaru, K, Koh, K. R, Ogata, M, Kikuchi, H, Sagara, Y, Uozumi, K, Mochizuki, M, Tsukasaki, K, Saburi, Y, Yamamura, M, Tanaka, J, Moriuchi, Y, Hino, S, \& Kamihira, S. Yamaguchi K; Joint Study on Predisposing Factors of ATL Development investigators. Blood. (2010). Aug; Human T-cell leukemia virus type I (HTLV-1) proviral load and disease progression in asymptomatic HTLV-1 carriers: a nationwide prospective study in Japan., $116,1211-1219$.

[21] Kannagi, R, Izawa, M, Koike, T, Miyazaki, K, \& Kimura, N. Cancer Sci. (2004). Carbohydrate-mediated cell adhesion in cancer metastasis and angiogenesis., 95, 377-384.

[22] Kawai, H, Kashiwagi, S, Sano, Y, Inui, T, \& Saito, S. Rinsho Shinkeigaku. (1991). HTLV-I associated myelopathy with Hashimoto's thyroiditis--a report of two cases., 31, 648-652.

[23] Kimura, I, Tsubota, T, Ueda, N, Tada, S, Yoshimoto, S, Sogawa, J, Shiraishi, T, Tamaki, T, Ueno, K, Fujita, T, et al. Nihon Kyobu Shikkan Gakkai Zasshi. (1989). Six cases of HTLV-I associated bronchiolo-alveolar disorder (HABA)., 27, 1074-1081.

[24] Kuno, A, Uchiyama, N, Ebe, K-K. u. n. o S, Takashima, Y, Yamada, S, \& Hirabayashi, M. J. Nature Methods, 2005; Evanescent-field fluorescence-assisted lectin microarray: a new strategy for glycan profiling. La Grenade L, Hanchard B, Fletcher V, Cranston 
B, Blattner W. Lancet. (1990). Infective dermatitis of Jamaican children: a marker for HTLV-I infection., 2, 851-856.

[25] Manns, A, \& Blattner, W. A. Transfusion. (1991). The epidemiology of the human Tcell lymphotrophic virus type I and type II: etiologic role in human disease., 31, 67-75.

[26] Mochizuki, M, Watanabe, T, Yamaguchi, K, Takatsuki, K, Yoshimura, K, Shirao, M, Nakashima, S, Mori, S, Araki, S, \& Miyata, N. Jpn J Cancer Res. (1992). HTLV-I uveitis: a distinct clinical entity caused by HTLV-I., 83, 236-239.

[27] Nakano, K, \& Watanabe, T. Nihon Rinsho. (2012). Apr; Current status and problems of anti-HTLV-1 drug development., 70(4), 671-5.

[28] Nasr, R, El Hajj, H, Kfoury, Y, De Thé, H, Hermine, O, \& Bazarbachi, A. Viruses. (2011). Controversies in targeted therapy of adult T cell leukemia/lymphoma: ON target or OFF target effects?, 3, 750-769.

[29] Nishioka, K, Maruyama, I, Sato, K, Kitajima, I, Nakajima, Y, \& Osame, M. Lancet. (1989). Feb 25;1(8635):441 Chronic inflammatory arthropathy associated with HTLVI.

[30] Olière, S, Douville, R, Sze, A, Belgnaoui, S. M, \& Hiscott, J. Cytokine Growth Factor Rev. (2011). Modulation of innate immune responses during human T-cell leukemia virus (HTLV-1) pathogenesis., 22, 197-210.

[31] Osame, M, Usuku, K, Izumo, S, Ijichi, N, Amitani, H, Igata, A, Matsumoto, M, \& Tara, M. Lancet. (1986). HTLV-I associated myelopathy, a new clinical entity., 1(8488), 1031-1032.

[32] Proietti, F. A, Carneiro-proietti, A. B, Catalan-soares, B. C, \& Murphy, E. L. Oncogene. (2005). Global epidemiology of HTLV-I infection and associated diseases., 24, 6058-6068.

[33] Rademacher, T. W, Parekh, R. B, \& Dwek, R. A. Annu. Rev. Biochem. (1988). Glycobiology., 57, 785-838.

[34] Ruben, S, Poteat, H, Tan, T. H, Kawakami, K, Roeder, R, Haseltine, W, \& Rosen, C. A. Science. (1988). Cellular transcription factors and regulation of IL-2 receptor gene expression by HTLV-I tax gene product., 241, 89-92.

[35] Sanada, I, Kawano, F, Tsukamoto, A, \& Kiyokawa, T. Rinsho Ketsueki. (1999). Adult T-cell leukemia with elevated serum hyaluronic acid levels paralleling disease activity., $40,51-54$.

[36] Sasaki, H, Nishikata, I, Shiraga, T, Akamatsu, E, Fukami, T, Hidaka, T, Kubuki, Y, Okayama, A, Hamada, K, Okabe, H, Murakami, Y, Tsubouchi, H, \& Morishita, K. Blood. (2005). Overexpression of a cell adhesion molecule, TSLC1, as a possible molecular marker for acute-type adult T-cell leukemia., 105, 1204-1213. 
[37] Satou, Y, Yasunaga, J, Zhao, T, Yoshida, M, Miyazato, P, Takai, K, Shimizu, K, Ohshima, K, Green, P. L, Ohkura, N, Yamaguchi, T, Ono, M, Sakaguchi, S, \& Matsuoka, M. PLoS Pathog. (2011). e1001274 HTLV-1 bZIP factor induces T-cell lymphoma and systemic inflammation in vivo.

[38] Sharon, N, \& Lis, H. Sci. Am. (1993). Carbohydrates in cell recognition., 268, 82-89.

[39] Shimoyama, M. Br J Haematol. (1991). Diagnostic criteria and classification of clinical subtypes of adult T-cell leukaemia-lymphoma. A report from the Lymphoma Study Group (1984-87)., 79, 428-437.

[40] Sonoda, S, Li, H. C, \& Tajima, K. Cancer Sci. (2011). Ethnoepidemiology of HTLV-1 related diseases: ethnic determinants of HTLV-1 susceptibility and its worldwide dispersal., 102, 295-301.

[41] Sowa, J. M. J Rheumatol. (1992). Human T lymphotropic virus I, myelopathy, polymyositis and synovitis: an expanding rheumatic spectrum., 19, 316-318.

[42] Teshigawara, K, Maeda, M, Nishino, K, Nikaido, T, Uchiyama, T, Tsudo, M, Wano, Y, \& Yodoi, J. J Mol Cell Immunol. (1985). Adult T leukemia cells produce a lymphokine that augments interleukin 2 receptor expression., 2, 17-26.

[43] Theocharis, A. D, Skandalis, S. S, Tzanakakis, G. N, Karamanos, N. K, \& Febs, J. (2010). Proteoglycans in health and disease: novel roles for proteoglycans in malignancy and their pharmacological targeting., 277, 3904-3923.

[44] Tsukasaki, K. Hematology. (2012). Suppl 1:S Adult T-cell leukemia-lymphoma., 32-35.

[45] Tsukasaki, K, Hermine, O, Bazarbachi, A, Ratner, L, \& Ramos, J. C. Harrington W Jr, O'Mahony D, Janik JE, Bittencourt AL, Taylor GP, Yamaguchi K, Utsunomiya A, Tobinai K, Watanabe T. J Clin Oncol. (2009). Definition, prognostic factors, treatment, and response criteria of adult T-cell leukemia-lymphoma: a proposal from an international consensus meeting., 27, 453-459.

[46] Varki, A. Glycobiology. (1993). Biological roles of oligosaccharides: All of the theories are correct., 3, 97-130.

[47] Varki, A, \& Faseb, J. (1997). Sialic acids as ligands in recognition phenomena., 11, 248-255.

[48] Van Beek, W. P, Smets, L. A, \& Emmelot, P. Nature. (1975). Changed surface glycoprotein as a marker of malignancy in human leukaemic cells., 253(5491), 457-460.

[49] Xu, Y. L, Adya, N, Siores, E, Gao, Q. S, \& Giam, C. Z. J Biol Chem. (1990). Cellular factors involved in transcription and Tax-mediated trans-activation directed by the TGACGT motifs in human T-cell leukemia virus type I promoter., 265, 20285-20292.

[50] Yamagishi, M, Nakano, K, Miyake, A, Yamochi, T, Kagami, Y, Tsutsumi, A, Matsuda, Y, Sato-otsubo, A, Muto, S, Utsunomiya, A, Yamaguchi, K, Uchimaru, K, Ogawa, S, 
\& Watanabe, T. Cancer Cell. (2012). Polycomb-mediated loss of miR-31 activates NIK-dependent NF- $\kappa B$ pathway in adult $\mathrm{T}$ cell leukemia and other cancers., 21, 121-135.

[51] Yamaoka, S, Courtois, G, Bessia, C, Whiteside, S. T, Weil, R, Agou, F, Kirk, H. E, Kay, R. J, \& Israël, A. Cell. (1998). Complementation cloning of NEMO, a component of the IkappaB kinase complex essential for NF-kappaB activation., 93, 1231-1240.

[52] Yeung, M. L, Yasunaga, J, Bennasser, Y, Dusetti, N, Harris, D, Ahmad, N, Matsuoka, M, \& Jeang, K. T. Cancer Res. (2008). Roles for microRNAs, miR-93 and miR-130b, and tumor protein 53-induced nuclear protein 1 tumor suppressor in cell growth dysregulation by human T-cell lymphotrophic virus 1. US Patent 6,787,364 (2004), 68, 8976-8985. 
